\title{
BMJ Open Self-reported oral health among a community sample of people experiencing social and health inequities: cross-sectional findings from a study to enhance equity in primary healthcare settings
}

\author{
Bruce Wallace, ${ }^{1}$ Annette J Browne, ${ }^{2}$ Colleen Varcoe, ${ }^{2}$ Marilyn Ford-Gilboe, ${ }^{3}$ \\ Nadine Wathen, ${ }^{4}$ Phoebe M Long, ${ }^{2}$ Joanne Parker ${ }^{2}$
}

To cite: Wallace $B$,

Browne AJ, Varcoe C, et al. Self-reported oral health among a community sample of people experiencing social and health inequities: crosssectional findings from a study to enhance equity in primary healthcare settings. BMJ Open 2015;5: e009519. doi:10.1136/ bmjopen-2015-009519

- Prepublication history for this paper is available online. To view these files please visit the journal online (http://dx.doi.org/10.1136/ bmjopen-2015-009519).

Received 23 July 2015 Revised 30 September 2015 Accepted 16 October 2015

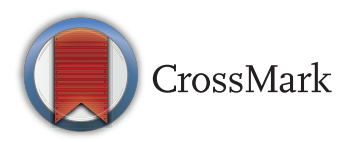

For numbered affiliations see end of article.

Correspondence to Dr Annette J Browne; annette.browne@nursing. ubc.ca

\section{ABSTRACT}

Objective: To describe the self-reported oral health issues among a community sample of primary care clients experiencing socioeconomic disadvantages.

Methods: As part of a larger mixed-methods, multiple case study evaluating an equity-oriented primary healthcare intervention, we examined the oral health of a sample of 567 people receiving care at four clinics that serve marginalised populations in two Canadian provinces. Data collected included selfrated oral health and experiences accessing and receiving healthcare, standard self-report measures of health and quality of life, and sociodemographic information.

Results: The prevalence of self-rated poor oral health was high, with almost half $(46.3 \%)$ of the participants reporting poor or fair oral health. Significant relationships were observed between poor oral health and vulnerabilities related to mental health, trauma and housing instability. Our findings suggest that the oral health of some Canadian populations may be dramatically worse than what is reported in existing population health surveys.

Conclusions: Our findings reinforce the importance of addressing oral health as part of health equity

strategies. The health and oral health issues experienced by this client cohort highlight the need for interdisciplinary, team-based care that can address the intersections among people's health status, oral health and social issues.

\section{INTRODUCTION}

Despite being identified as a national priority in Canada, ${ }^{1}$ little progress has been made in understanding oral health within the context

\section{Strengths and limitations of this study}

- The multiple case study design allowed us to collect data from a large cohort, across several sites; this is an important data set given the challenges of recruiting people to participate in studies such as this.

- The oral health of populations experiencing significant socioeconomic disadvantages and vulnerabilities may be much greater than presumed based on population health surveys where marginalised populations are underrepresented.

- This study does not infer any causal relationships between perceived poor oral health and health and social vulnerabilities. The measurement of poor oral health is limited to self-reports and not clinical data. Individual ratings of oral health may be positively skewed as visible decay was commonly noticed by interviewers with participants reporting nonproblematic oral health.

- Owing to the lack of availability of translation services, only those clients who could understand and speak English were eligible to participate in this study.

of growing health and social inequities. In this paper, we examine the association between self-rated oral health and a range of complex health and social issues in a community sample of clients from four primary healthcare (PHC) clinics in two provinces in Canada. Our aim is to explore the interconnections between oral health and various health and social inequities. 
Oral health inequities in Canada: policy and healthcare context

Oral health inequities ${ }^{\mathrm{i}}$ are significant in Canada. As in other countries, these inequities are largely related to income. ${ }^{4-6}$ Lower-income Canadians, including those with no dental insurance or with only public dental health benefits, are most likely to need dental care and most likely to not obtain such care due to costs. ${ }^{1} 7$ Out-of-pocket spending on dental care has been increasing, and those increases are greatest among those least able to afford such costs, with Canada's lowest income households experiencing a $60 \%$ increase in out-of-pocket spending on dental care between 1997 and 2009. ${ }^{8}$ Moreover, low-income households typically spend a much higher percentage of income on healthcare costs than more affluent households. ${ }^{8}$ These oral health inequities are particularly concerning, given Canada's 2014 ranking as the OECD (Organization for Economic Co-operation and Development) nation with the second highest level of income inequities, surpassed only by the USA. ${ }^{9}$

Health and social inequities result from structural conditions and policies that contribute to segments of the population being more likely to report and have documented poor oral health. In Canada, this includes Indigenous ${ }^{\mathrm{ii}}$ people, people who are homeless, those classified as the working poor and elderly persons. For example, First Nations populations have higher rates of dental decay and tooth loss compared to the general Canadian population, ${ }^{11}$ and Inuit populations have poorer oral health and higher frequency of food avoidance because of oral pain than the general Canadian population south of the 60 th parallel. ${ }^{12}$ Research among adults who are homeless has found much poorer oral health, significant unmet treatment needs and a lack of access to dental care. ${ }^{13}$ While oral health inequities are most evident among groups who are most economically disadvantaged, the working poor-who live in relative poverty-frequently have no dental insurance coverage and report poor oral health and visits to a dentist only in emergencies. ${ }^{14}{ }^{15}$ Analysis of Canadian Health Measures Survey data from 2007 to 2009 revealed that among elderly Canadians, income-related oral health inequities are intensified, especially for those without insurance and the frail elderly. ${ }^{16}$ Overall, adults with vulnerabilities and complex care needs face multiple barriers to accessing necessary oral health preventive care and treatment. ${ }^{17} 18$

Oral health inequities reflect both wider economic inequities and limitations in Canada's system of dental

\footnotetext{
${ }^{\mathrm{i}}$ The terms inequity, inequality and disparity are used differently in various contexts internationally. ${ }^{2}$ In this paper, we use the term inequity to refer to differences among groups that are due to unfair social arrangements that are potentially remediable. ${ }^{3}$

ii Indigenous people in Canada are often referred to as 'Aboriginal' peoples, and include First Nations, Métis and Inuit populations. ${ }^{10}$ In this paper, we use the term Indigenous unless reporting on specific population groups.
}

care. Canada has a single model of dental delivery, under which most Canadians purchase their dental care from dental professionals in privately owned and operated practices. Most individuals pay out-of-pocket, or through private dental insurance from their place of employment. Approximately $60 \%$ of Canadians are covered by employment-related plans and about a third have no dental insurance. ${ }^{1}$

\section{Oral health policies: impact on provision of services}

Although public oral health is ostensibly a priority, there is little public financing of dentistry in Canada and private spending continues to increase more rapidly than public spending. ${ }^{19}$ Only $5 \%$ of Canadians receive public dental health benefits, which are limited dental insurance plans targeting specific populations, typically people on social assistance and status First Nations people. Unlike medical services, dental services are not included in Canada's universal Medicare system ${ }^{\mathrm{iii}}$ and are not publicly covered for the general population. While almost all $(98.6 \%)$ of physician services are reimbursed with public funds, only about $6 \%$ of all dental expenditures are publicly funded in Canada. ${ }^{1}$

The provision of public dental benefits does not always ensure access to dental care for those who are covered, in part because of the complexity of insurance-related barriers to accessing dental treatment. ${ }^{17}$ 20-22 Further, even when people do access dental care through public benefits, the quality of that care may be inferior to that offered to those paying out of pocket or through employment and private insurance. Dentists express their reluctance to accept clients with public dental benefits; ${ }^{23}$ and missed appointments by low-income clients tend to result in exclusion strategies. ${ }^{24}$ The relationship between dentists and low-income clients has been described as fraught with therapeutic, relationship, financial, personal and systemic failures. ${ }^{24}$

In summary, though urgently needed, dental care provision to people experiencing social inequities is hampered by the fact that the majority of the Canadian population is adequately served, ${ }^{1}$ and by the fact that dental care is 'hived off' from healthcare more generally by policy and practices in the Canadian system. Even though the role of oral health in overall health is incontrovertible and the contribution of poor oral health to healthcare costs is well documented, ${ }^{25}$ dental care is not treated as essential in Canadian policy and funding structures.

The purpose of this paper is to describe the selfreported oral health issues among a community sample of primary care clients experiencing socioeconomic disadvantages. We use Canadian population estimates to

\footnotetext{
${ }^{i i i}$ However, the Federal government is responsible for provision of dentistry to Aboriginal peoples, the national police (RCMP) and Canadian Forces personnel and veterans. ${ }^{1}$
} 
compare the self-rated oral health from the sample population to rates reported in the general population. As we discuss, identifying the intersections among oral health status and other forms of vulnerability can highlight the importance of addressing oral health inequities within the Canadian healthcare system, and inform strategies to enhance capacity for equity-oriented oral healthcare delivery with populations who can be considered marginalised $^{\text {iv }}$.

\section{METHODS}

\section{Design and settings}

We report specific baseline findings from a larger study known as the EQUIP research programme. ${ }^{26}$ The EQUIP study uses a mixed methods, multiple case study design to evaluate the effectiveness of an innovative, multicomponent intervention to enhance capacity for equity-oriented PHC services at four PHC clinics (two each in British Columbia (BC) and Ontario) that serve populations experiencing various forms of social disadvantage. The clinics were selected to achieve diversity in five domains of context. Specifically, the sites are located in diverse geographic areas, serve different populations and have different interdisciplinary staff complements, funding mechanisms and clinic histories and policies. The BC clinics primarily serve inner city marginalised populations. One of the Ontario clinics serves lowincome families, including new immigrants and refugees in an urban and suburban context and the other serves people residing in a rural region of southern Ontario. All four clinics provide primary care and social support services to diverse groups of clients, with the majority of clients experiencing social disadvantages ranging from low income, lack of affordable housing and unemployment, histories of violence and/or trauma, or the inability to work due to significant physical or mental health issues. In 2013, the combined client population served by the four clinics was approximately 12000 people.

\section{Sampling and recruitment}

Participants were eligible to participate based on the following inclusion criteria: at least 18 years of age, able to understand and speak English, had at least three visits to one of the participating clinics in the past 12 months and intended to continue accessing services at the clinic for the next 2 years. People meeting the inclusion criteria who came to access services at the clinic on purposively selected days were invited to participate. To enhance representativeness, we ensured that people who had scheduled appointments and those who dropped in for an appointment or came into the clinic for another purpose were eligible to participate. A sample of 120160 people was recruited from each site, comprising a

\footnotetext{
iv We use the terms 'marginalisation' or 'marginalised' to refer to the social, political and economic conditions that create health, social and health care inequities.
}

cohort of 567 clients who are being followed at four time points over a 3-year period. The demographic characteristics of the EQUIP sample are shown in table 1.

Table 1 EQUIP participant demographics $(\mathrm{N}=567)$

\begin{tabular}{|c|c|c|c|}
\hline & $\mathbf{n}$ & $\begin{array}{l}\text { Per } \\
\text { cent }\end{array}$ & Mean (SD) \\
\hline Gender & 567 & & \\
\hline Male & 236 & 41.6 & \\
\hline Female & 329 & 58.0 & \\
\hline Transgender & 2 & 0.4 & \\
\hline Age & 545 & & $\begin{array}{l}45.5(14.6) \\
\text { (range: } \\
18-94)\end{array}$ \\
\hline Aboriginal identity & 558 & & \\
\hline Yes & 244 & 43.7 & \\
\hline No & 314 & 56.3 & \\
\hline Relationship with a partner & 547 & & \\
\hline Yes & 265 & 48.4 & \\
\hline No & 282 & 51.6 & \\
\hline Employment status & 534 & & \\
\hline Employed* & 108 & 20.2 & \\
\hline Unemployed & 349 & 65.4 & \\
\hline Other† & 77 & 14.4 & \\
\hline Educational level & 548 & & \\
\hline Less than high school & 238 & 43.4 & \\
\hline Completed high school & 81 & 14.8 & \\
\hline $\begin{array}{l}\text { Postsecondary up to and } \\
\text { including undergraduate } \\
\text { degree }\end{array}$ & 199 & 36.3 & \\
\hline $\begin{array}{l}\text { Professional/graduate level } \\
\text { degree }\end{array}$ & 16 & 2.9 & \\
\hline Other & 14 & 2.6 & \\
\hline Receiving social assistance & 168 & 29.6 & \\
\hline Receiving disability assistance & 223 & 39.3 & \\
\hline $\begin{array}{l}\text { Difficulty living on TOTAL } \\
\text { household income } \neq\end{array}$ & 543 & & \\
\hline Very difficult & 197 & 36.3 & \\
\hline Somewhat difficult & 183 & 33.7 & \\
\hline Not very difficult & 96 & 17.7 & \\
\hline Not at all difficult & 67 & 12.3 & \\
\hline Living situation§ & 548 & & \\
\hline Market housing & 331 & 60.4 & \\
\hline Non-market housing & 217 & 39.7 & \\
\hline Shelter usage (past 12 months) & 539 & & \\
\hline Yes & 142 & 26.3 & \\
\hline No & 397 & 73.7 & \\
\hline \multicolumn{4}{|c|}{$\begin{array}{l}\text { *'Employed' status includes individuals working full-time or } \\
\text { part-time, as well as those taking part in seasonal work. } \\
\text { †The majority of responses in this category are: retired, disability } \\
\text { assistance, stay-at-home mom, student and self-employed or } \\
\text { occasional cash work. } \\
\text { łParticipants were asked: Overall, how difficult is it for you to live } \\
\text { on your total household income right now? } \\
\text { §Market housing includes individuals living in a private apartment, } \\
\text { condo or house. Non-market housing includes individuals who } \\
\text { reported living in public, social or supportive housing, those } \\
\text { couch-surfing, living in shelters, on the street, in a vehicle, in a } \\
\text { single-room occupancy hotel and those who chose 'other' in lieu } \\
\text { of the above options. }\end{array}$} \\
\hline
\end{tabular}




\section{Data collection and measurement}

Baseline data collection occurred in 2013. Trained researchers obtained participants' written informed consent prior to completing a structured interview using a computer-assisted data platform on a tablet computer. Participants were provided with an honorarium to acknowledge the time and effort required to participate in the study. Data collected included, for example: (1) clients' experiences accessing healthcare and receiving care at the clinics, (2) two items on self-rated oral health ${ }^{\mathrm{v}}$ from the Canadian Community Health Survey (CCHS) ${ }^{28}$ and (3) standard measures of health and quality of life, including the CESD-R ${ }^{29-31}$ depression screening tool, the Von Korff Chronic Pain Grade Scale $^{32}$ and the PCL-C Symptoms of Trauma Checklist. ${ }^{33}{ }^{34}$ Sociodemographic information, including housing status and a measure of financial strain, was also collected.

\section{Data analysis}

Using SPSS (V.21), frequencies were calculated to describe the demographic and socioeconomic characteristics of the sample population at baseline, with a focus on oral health. Descriptive statistics (mean, SD, median, range) were used to summarise continuous variables. To test associations between oral health and our variables of interest, we used the chi-square test $\left(\chi^{2}\right)$ and Spearman's rho $\left(r_{s}\right)$. Associations were deemed significant at a level of $\mathrm{p}<0.05$.

\section{RESULTS}

\section{Description of participants}

Over half of the 567 participants were female and ages ranged from 18 to 94 years, with the mean age being 45 years $(\mathrm{SD}=14.6)$. A high proportion identified as Aboriginal. Clinics participating in this study have explicit mandates to serve populations that are disadvantaged by structural and social inequities, and this mandate is reflected in the sample demographics. Comparisons with electronic medical records and administrative data, as well as consultations with clinic leads, suggest that our sample is representative of the overall client population at each site in terms of gender, age range, ethnocultural background and socioeconomic status.

Compared with the general population in Canada, we observed some specific vulnerabilities and complexities within our sample. They were predominantly unemployed (65.4\% compared to $7.1 \%$ in Canada in $2013)^{35}$ and receiving either social assistance or disability benefits $(68.9 \%$ compared to $6-7 \%$ of the Canadian population receiving social assistance in 2012). ${ }^{36}$

\footnotetext{
${ }^{\mathrm{v}}$ These questions ask about overall oral health using a five-point scale from excellent to poor, and frequency of pain or discomfort in teeth or gums in the past month using a four-point scale from often to never. They are derived from the oral health component of the Canadian Health Measures Survey (CHMS) ${ }^{27}$
}

Economic hardships were reported by the majority of participants, with nearly $70 \%$ reporting it was somewhat or very difficult to live on their income. In contrast, $8.8 \%$ of Canadians were considered Low Income (LIM-AT) $^{\mathrm{vi}}$ in 2011(the most current year available). ${ }^{37}$ While most participants lived in some form of market housing (tenants in privately-owned rental properties or homeowners), a significant proportion lived in nonmarket housing situations including public, social and supportive housing. Overall, housing vulnerabilities were significant, with more than a quarter of participants reporting having spent one or more nights in a shelter in the past year, while approximately 1 in 230 Canadians $(0.4 \%)$ were reported to have stayed in an emergency shelter at least once in 2009. ${ }^{38} 39$

Over one-third of participants rated their general health as fair or poor, as shown in table 2, and a similar proportion of participants expressed fair or poor mental health $(31.2 \%)$. Many participants reported having problems related to substance use and significant numbers of participants were living with HIV/AIDS and/or hepatitis C. About one in four participants had experienced a significant head injury. Rates of other chronic illnesses were also higher than rates observed in the general population. For example, in our sample participants reported having been diagnosed or treated with various chronic conditions at higher rates than the general Canadian population in 2013: depression $(52.5 \%$ vs $7.6 \%$ reporting a mood disorder $\left.{ }^{\mathrm{vii}}\right)$, arthritis $(38.6 \%$ vs $15.9 \%)$, high-blood pressure $(31.8 \%$ vs $17.7 \%)$, diabetes $(13.2 \%$ vs $6.6 \%){ }^{40}$

\section{Oral health}

Overall, we found high prevalence of self-rated poor oral health. For the purposes of comparison, we collapsed self-rated oral health into two categories: 'Poor', which includes responses of fair and poor; and 'Good', which includes responses of good, very good and excellent. In total, 556 participants provided a response to the questions rating their overall oral health and frequency of pain or discomfort in teeth or gums in the past month (table 3). Almost half of the participants (46.4\%) reported Poor oral health. Nearly half of participants (44.1\%) reported sometimes or often experiencing oral pain or discomfort in the past month. These results indicate substantially higher prevalence of self-rated Poor oral health and oral pain or discomfort compared to the general Canadian population $(15.5 \%$ and $11.6 \%$, respectively). ${ }^{1}$ Furthermore, we suspect that participants' assessment of their own oral health may be positively

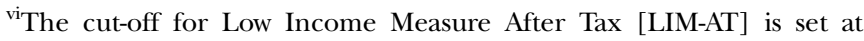
$50 \%$ of median adjusted after-tax income, where 'adjusted' indicates that a household's needs are taken into account. ${ }^{37}$

${ }^{\text {vii }}$ Statistics Canada reports this as the "population aged 12 and over who reported that they have been diagnosed by a health professional as having a mood disorder, such as depression, bipolar disorder, mania or dysthymia." 40
} 
Table 2 Self-reported health $(\mathrm{N}=567)$

\begin{tabular}{|c|c|c|}
\hline & $\mathbf{n}$ & Per cent \\
\hline General health & 556 & \\
\hline Poor & 54 & 9.7 \\
\hline Fair & 147 & 26.4 \\
\hline Good & 215 & 38.7 \\
\hline Very good & 108 & 19.4 \\
\hline Excellent & 32 & 5.8 \\
\hline General health, dichotomised & 556 & \\
\hline Poor or fair & 201 & 36.2 \\
\hline Good to excellent & 355 & 63.8 \\
\hline $\begin{array}{l}\text { Chronic health conditions, diagnosed or } \\
\text { treated }^{*}\end{array}$ & 512 & \\
\hline None & 33 & 6.4 \\
\hline One & 82 & 16.0 \\
\hline Two or more & 397 & 77.5 \\
\hline \multicolumn{3}{|c|}{ Frequency of selected chronic health conditions* } \\
\hline Depression $(n=550)$ & 289 & 52.5 \\
\hline Anxiety $(n=547)$ & 265 & 48.4 \\
\hline Substance use problems $(n=544)$ & 223 & 41.0 \\
\hline Arthritis $(n=544)$ & 210 & 38.6 \\
\hline High-blood pressure $(n=548)$ & 174 & 31.8 \\
\hline Head injury $(n=549)$ & 138 & 25.1 \\
\hline Hepatitis C $(n=547)$ & 123 & 22.5 \\
\hline Diabetes $(n=546)$ & 72 & 13.2 \\
\hline Heart disease $(n=550)$ & 57 & 10.4 \\
\hline HIV/AIDS $(n=546)$ & 48 & 8.8 \\
\hline
\end{tabular}

skewed. Interviewers commonly noticed visible decay among participants reporting non-problematic, or Good, oral health.

Table 4 shows comparative percentages of adults' selfrated Poor oral health from our community sample and the CHMS, ${ }^{1}$ as well as related surveys of specific subpopulations. As shown below, the proportion of EQUIP participants with Poor oral health is almost twice that found in other economically vulnerable populations and those receiving public dental benefits. The extent of Poor oral health among our sample is greater than that

Table 3 Self-reported measures of oral health and associated health measures $(\mathrm{N}=567)$

\begin{tabular}{lrl}
\hline & $\mathbf{n}$ & Per cent \\
\hline Oral health & 556 & \\
Poor & 132 & 23.7 \\
Fair & 126 & 22.7 \\
Good & 151 & 27.2 \\
Very good & 88 & 15.8 \\
Excellent & 59 & 10.6 \\
Pain or discomfort in teeth and mouth & 556 & \\
$\quad$ Never & 213 & 38.3 \\
Rarely & 98 & 17.6 \\
Sometimes & 135 & 24.3 \\
Often & 110 & 19.8 \\
\hline
\end{tabular}

Table 4 Percentage of respondents rating their oral health as fair or poor in EQUIP and other Canadian population surveys*

EQUIP sample
2013 (N=567)
Adults aged 18-94
Canadian Health Measures Survey ${ }^{1}$
$2007-2009$ (N=5586)
Canadians aged 6-79
Lower income
Middle income
Higher income
Not insured
Publicly insured $\dagger$
Privately insured

$46.4 \%$

First Nations Oral Health Survey ${ }^{11}$

2009-2010 ( $\mathrm{N}=1188$ )

First Nations adolescents and adults aged $12+$

$38.7 \%$

Inuit Oral Health Survey ${ }^{12}$

2008-2009 ( $\mathrm{N}=1216)$

Inuit young adults (20-39 years)

Inuit adults (40 years + )

$40.7 \%$ $38.6 \%$

Toronto Adult Homeless Survey ${ }^{13}$

2010 ( $\mathrm{N}=191)$

Adults aged $18-75$

$60.2 \%$

*Percentages shown here reflect self-reported fair or poor oral health on the Canadian Health Measures Survey Oral Health Component.

†Public dental insurance plans target specific populations, typically people on social assistance and status First Nations people.

found in Canadian Aboriginal population surveys such as the First Nations Oral Health Survey ${ }^{11}$ and the Inuit Oral Health Survey. ${ }^{12}$ A survey of Toronto's homeless adults ${ }^{13}$ reported $60.2 \%$ of participants experiencing Poor oral health, which is higher than our overall findings. However, these rates are consistent with the EQUIP participants who were homeless and recently homeless. Poor oral health was reported by $62.9 \%$ of participants who stayed in a shelter in the past 12 months, and by $61.9 \%$ of participants with a current living situation of couch-surfing, shelter, on the street, in a vehicle or in a single-room occupancy hotel).

We examined the associations between self-rated oral health and other health and social indicators. Again, we collapsed self-rated oral health into two categories of Poor and Good. Overall, we observed that those participants experiencing greatest health and social vulnerabilities were more likely to report their oral health as Poor.

Reports of Poor oral health were not related to age or gender. Poor oral health was significantly associated with Aboriginal identity, and with self-reported fair or poor mental health and general health (see table 5). Furthermore, participants reporting Poor oral health were significantly more likely to report high levels 
Table 5 Associations between self-reported Poor oral health and social and health variables $(\mathrm{N}=567)$

\begin{tabular}{|c|c|c|c|c|}
\hline & $\begin{array}{l}\text { Poor oral } \\
\text { health }(n)^{*}\end{array}$ & $\begin{array}{l}\text { Poor oral } \\
\text { health }(\%)^{\star}\end{array}$ & Test statistic & p Value \\
\hline General health, dichotomised & & & $\chi^{2}$ Yates $=21.56$ & $<0.001$ \\
\hline Fair or poor & 120 & 59.7 & & \\
\hline Good to excellent & 138 & 38.9 & & \\
\hline Mental health, dichotomised & & & $\chi^{2}$ Yates $=12.29$ & $<0.001$ \\
\hline Fair or poor & 100 & 57.8 & & \\
\hline Good to excellent & 158 & 41.4 & & \\
\hline Disabling chronic pain $†$ & & & $\chi^{2}$ Yates $=18.66$ & $<0.001$ \\
\hline No pain (grades $0-I I)$ & 97 & 36.7 & & \\
\hline Pain (grades (III-IV) & 148 & 55.8 & & \\
\hline PTSD symptoms (PCL-C)‡ & & & $\chi^{2}$ Yates $=16.55$ & $<0.001$ \\
\hline No or low symptoms (below threshold) & 70 & 34.4 & & \\
\hline Probable PTSD & 181 & 52.6 & & \\
\hline Depressive symptoms (CESD-R)§ & & & $\chi^{2}$ Yates $=8.92$ & 0.003 \\
\hline No depressive symptoms & 103 & 39.0 & & \\
\hline Some depressive symptoms & 147 & 52.1 & & \\
\hline Depression (self-reported) & & & $\chi^{2}$ Yates $=8.28$ & 0.004 \\
\hline No & 103 & 39.6 & & \\
\hline Yes & 150 & 52.1 & & \\
\hline Anxiety (self-reported) & & & $\chi^{2}$ Yates $=6.81$ & 0.009 \\
\hline No & 114 & 40.6 & & \\
\hline Yes & 138 & 52.1 & & \\
\hline HIV/AIDS (self-reported) & & & $\chi^{2}$ Yates $=6.48$ & 0.011 \\
\hline No & 220 & 44.3 & & \\
\hline Yes & 31 & 64.6 & & \\
\hline Hepatitis C (self-reported) & & & $\chi^{2}$ Yates $=9.80$ & 0.002 \\
\hline No & 180 & 42.5 & & \\
\hline Yes & 72 & 59.0 & & \\
\hline Shelter (accessed past 12 months) & & & $\chi^{2}$ Yates $=20.56$ & $<0.001$ \\
\hline No & 159 & 40.2 & & \\
\hline Yes & 88 & 62.9 & & \\
\hline Living situation & & & $\chi^{2}$ Yates $=10.34$ & 0.001 \\
\hline Market housing & 132 & 40.0 & & \\
\hline Non-market housing & 105 & 55.0 & & \\
\hline Overall financial strain** & & & $\chi^{2}$ Yates $=37.09$ & $<0.001$ \\
\hline Not difficult & 41 & 25.3 & & \\
\hline Difficult & 205 & 54.2 & & \\
\hline Gender^ & & & $\chi^{2}=2.91$ & 0.088 \\
\hline Male & 118 & 50.9 & & \\
\hline Female & 139 & 43.2 & & \\
\hline Age & & & $r_{\mathrm{s}}=0.026$ & 0.548 \\
\hline Aboriginal identity & & & $\chi^{2}$ Yates $=5.38$ & 0.020 \\
\hline Yes & 125 & 52.3 & & \\
\hline No & 131 & 42.0 & & \\
\hline
\end{tabular}

*Where reported frequencies add up to less than the total $n$ for Poor oral health, and/or percentages do not add up to 100 , this is due to missing data.

${ }^{\dagger}$ Chronic pain grade, as scored on the Von Korff chronic pain scale, ${ }^{32}$ which classifies pain from grade 0 (pain free) to IV (high disability-severely limiting).

${ }^{\ddagger}$ Scores from the post-traumatic stress disorder (PTSD) Checklist, Civilian Version (PCL-C) ${ }^{33}{ }^{34}$ were compared against a predetermined cut score of 35 to determine which people were experiencing high levels of trauma symptoms.

§Participants' total Centre for Epidemiologic Studies Depression Scale Revised (CESD-R) ${ }^{29-31}$ scores were collapsed into categories of No depressive symptoms and Some depressive symptoms, based on an overall cut score of 16 .

"Market housing includes individuals living in a private apartment, condo or house. Non-market housing includes individuals who reported living in public, social or supportive housing, those couch-surfing, living in shelters, on the street, in a vehicle, in a single-room occupancy hotel and those who chose 'other' in lieu of the above options.

${ }^{\star *}$ Not difficult includes responses of Not at all difficult and Not very difficult. Responses of Very difficult and Somewhat difficult were collapsed into Difficult.

${ }^{\wedge}$ Two participants identified as transgender; however, their cases were excluded from this specific test due to insufficient data. 
of chronic pain, severe trauma symptoms or probable clinical depression. Similarly, there were statistically significant associations between Poor oral health and a diagnosis of depression, anxiety, HIV/AIDS, or hepatitis C. Poor oral health was also significantly associated with poor living situation. People who had accessed a shelter in the past year were more likely to report Poor oral health than those who had not. Similarly, people who were currently homeless or living in public, social or supportive housing were more likely to report Poor oral health than people residing in market housing.

\section{DISCUSSION}

Our study adds to existing knowledge of oral health inequities within the Canadian population by exploring the self-reported oral health of a community sample of people experiencing a high degree of material and social disadvantages. Given the challenges of including marginalised people in health surveys, the EQUIP study addresses a gap in our current knowledge regarding selfreported oral health among vulnerable populations. On the whole, our findings suggest that the oral health of some Canadian populations may be dramatically worse than what is reported in existing population health surveys. Correspondingly, inequities in oral health may be much greater than presumed based on previous health surveys where marginalised populations are under-represented.

This study used self-assessed oral health rather than objective measures of oral diseases and untreated dental needs. However, previous research has demonstrated the adequacy of the subjective measure in predicting objective dental needs ${ }^{41}$ and the links between the measure of self-rated poor oral health and the complexities of experiencing poverty. ${ }^{42}$ While self-rated oral health is a limited measure of oral health, it is a significant predictor of having unmet dental treatment needs. ${ }^{41}$ For example, data from the CHMS found that people reporting fair or poor oral health were 5.9 times more likely to have an unmet dental treatment need than those reporting excellent or good oral health. ${ }^{42}$ Indeed, secondary analysis of CHMS data has indicated that $67.8 \%$ of individuals reporting fair or poor oral health were deemed to have a clinically determined treatment need, with nearly half $(46 \%)$ requiring restorative treatment. ${ }^{41}$ Given the extent of self-rated poor oral health in the EQUIP sample, it is likely that participants have a high degree of unmet dental treatment needs. The complexity of those needs also warrants attention, given the significant associations we found between reports of poor oral health and issues related to mental health, trauma and substance use, as well as HIV/AIDS, hepatitis C and head injury.

People's self-reported oral health status is inextricably linked to other types of health inequities including the interconnected issues of low income, inadequate, unstable or unsafe housing and the complex health needs that frequently accompany these social inequities. The analysis presented in this paper is not meant to infer causal effects between perceived poor oral health and the health and social vulnerabilities explored in the data. The client sample for this study includes four primary healthcare sites in two Canadian provinces and generalisations to other jurisdictions may be limited by considerations such as dental and general health insurance policies. However, our findings illustrate disproportionately poor oral health among a segment of the population experiencing multiple chronic health conditions, high rates of mental health and substance use issues, and high rates of depression and symptoms of trauma, as well as economic and housing vulnerabilities.

Based on our experiences conducting the face-to-face interviews, we suspect that participants' ratings of their own oral health may have been positively skewed. Our interviewing team observed that many participants have very few remaining teeth, because they have had multiple extractions and many of these participants reported that their dental health was consequently no longer problematic. Owing to the extent or severity of oral health problems in this population, people may have rated their oral health positively relative to the oral health of their peers or to the pain and discomfort they may have experienced in the past. In future, the integration of an objective measure of oral health may be needed to show the extent of unmet dental needs despite self-reported ratings.

These findings suggest that oral health inequities are shaped by complex factors in addition to and beyond direct economic circumstances. The findings show that oral health inequities are associated with vulnerabilities related to mental health, trauma, substance use and housing instability. These will need to be addressed as intersecting health and social conditions. Without attention to the complex interplay among these issues, intersecting health and social inequities may persist even if financial barriers to accessing dental care are reduced through greater access to public dental benefits and related policy responses.

Our study raises questions as to the effectiveness of increasing public dental insurance coverage as a single response to improve access and equity within the current private practice delivery model. ${ }^{7}$ While such public investment in dental care is critical, it may not be adequate to address the vulnerabilities such as those experienced by the participants in this study. Given the barriers to healthcare access including stigma experienced by people with mental health problems, trauma histories, substance use problems and housing instability, ${ }^{43-47}$ how and where dental treatment is provided must also be considered to ensure responsiveness to such marginalising issues.

In Quebec, Canada, researchers have identified that dental care providers lack awareness of the realities and complexities experienced by people living on social welfare, and that misconceptions and negative 
stereotypes operate to create barriers to accessing care. ${ }^{48}$ At the same time, people on social assistance from that province express critical opinions of dentists and describe stereotypes of insensitive dentists who are more motivated by money than the health of their clients. ${ }^{22}$ Indeed, research with clients and providers has uncovered a poor fit between private practice dentistry, public dental benefits and the oral health needs of low-income communities. Both dentists and low-income clients express dissatisfaction with the financial barriers to providing and accessing care as well as sociocultural conflicts when dental offices are ill-equipped to provide care to people with complex health issues who experience marginalisation. ${ }^{17}$

The complexities of care and severity of vulnerabilities affecting populations experiencing socioeconomic disadvantages and marginalisation challenge the ability and capacity of the existing model of dental practice in Canada to effectively ensure access and appropriate care. ${ }^{21}$ Recommendations to address oral health inequities need to address these complexities. For example, proportionate universality ${ }^{\text {vii }}$ approaches are advised to best address the social gradient of oral health inequities and effectively tailor interventions to the needs of vulnerable groups. ${ }^{48} 51$ While researchers and policy leaders continue to advocate for population-level responses to reduce financial barriers and work towards universal coverage in oral health, there is growing recognition of the need for strategies that are responsive to the complex needs of more marginalised groups. ${ }^{21} 51$ One such recommendation for underserved populations is the effective integration of dental services with primary care and public health in community-based care. $^{53}$

Beyond expanded and enhanced public dental benefits, there is a need for oral health services for marginalised communities that seek to ensure accessible, appropriate and effective dental treatment. ${ }^{21} 51$ The health and oral health issues experienced by the EQUIP client cohort highlight the need for interdisciplinary responses that can address the intersections among people's health, oral health and social issues in settings that foster safety and trust. Common models and solutions including charitable dentistry and volunteer-based dental clinics, which typically provide one-off, acute dental interventions (often extractions) are likely inadequate to respond to such complexities. We therefore question whether charitable dentistry, volunteerism and responses that are limited to emergency care can be considered health equity interventions. They are not capable

\footnotetext{
viii As described by Marmot et al, "To reduce the steepness of the social gradient in health, actions must be universal, but with a scale and intensity that is proportionate to the level of disadvantage. We call this proportionate universalism. Greater intensity of action is likely to be needed for those with greater social and economic disadvantage, but focusing solely on the most disadvantaged will not reduce the health gradient, and will only tackle a small part of the problem." ${ }^{49}$, p. 10
}

of providing oral healthcare as part of a broader approach to supporting people's overall health status, or of serving as a safety net for underserved and vulnerable populations. ${ }^{54}$

We recommend the integration of oral healthcare with general healthcare at several levels to best respond to shared risk factors and determinants of health experienced by people living with complex vulnerabilities. First, integration of oral health benefits within universal health insurance would likely provide the most value across the social gradient of oral health inequities, notably to working poor populations. Second, we encourage integration of dental treatment within alternate healthcare settings such as community health centres that seek to provide trauma- and violence-informed, culturally-safe, equitable health services to marginalised populations. ${ }^{55}$ Finally, oral health ought to be integrated within considerations of health equity: from assessing inequities to developing and implementing policies and practices, oral health needs to be better incorporated into the health equity agenda. Overall, action on oral health inequities requires integration within action on general health inequities, which includes attention to proportionate universality and tailoring of responses.

Further research aimed at applying an equity lens to oral health could collect clinical data to determine the oral health needs of marginalised populations as well as self-assessed oral health measures. Having standardised clinical measures such as Decayed/Missing/Filled Teeth (DMFT) scores and counts of untreated dental conditions would allow further population level comparisons. Explorations of the effectiveness of primary healthcare settings designed to serve marginalised populations may further inform innovations in community dentistry and policy frameworks to foster the integration of dentistry in equity-oriented healthcare.

\section{CONCLUSION}

The extent of poor oral health among populations experiencing significant socioeconomic disadvantages and vulnerabilities may be much greater than presumed based on population health surveys where marginalised populations are under-represented. Poor oral health was reported by almost half $(46.3 \%)$ of the EQUIP participants, with significant relationships observed between Poor oral health and many of the vulnerabilities and health issues faced by this population. Better understanding of the intersections among oral health status and other forms of health inequities can highlight the importance of addressing oral health inequities within the Canadian healthcare system, and inform strategies to enhance capacity for equity-oriented oral healthcare delivery with marginalised populations.

Author affiliations

${ }^{1}$ School of Social Work, University of Victoria, Victoria, British Columbia, 
Canada

${ }^{2}$ School of Nursing, University of British Columbia, Vancouver, British Columbia, Canada

${ }^{3}$ Arthur Labatt Family School of Nursing, Western University, London, Ontario, Canada

${ }^{4}$ Faculty of Information \& Media Studies, Western University, London, Ontario, Canada

Acknowledgements The authors would like to thank the people in the EQUIP study who have generously shared their time and experiences with us. The EQUIP project would not be possible without the dedicated efforts and valuable contributions of the EQUIP research team, including our research partners and clinical site collaborators. In particular, the authors are grateful to Beth Jackson for encouraging us to explore oral health through an equity lens, and the leads at our four participating sites: Kathy Bresett, Margaret Coyle, Anne Drost, Myrna Fisk, Irene Haigh-Gidora and Murry Krause. The authors also thank Joanne Parker, Kelsey Timler and Joanne Hammerton for their contributions to data collection, analysis and interpretation, as well as editing support.

Contributors AJB is the Nominated Principal Investigator for the EQUIP research programme and CV, MF-G and NW are coprincipal investigators. BW is currently a coinvestigator, and at the time of writing this manuscript was a post-doctoral fellow. BW, CV and AJB co-led the development of the manuscript and data analysis and interpretation. MF-G and NW contributed to the data interpretation and manuscript development. PML and JP coordinated the editing and contributed to all drafts of this manuscript.

Funding This work was supported by Canadian Institutes of Health Research (http://www.cihr-irsc.gc.ca) grant number ROH-115210.

Competing interests None declared.

Ethics approval University of British Columbia Behavioural Research Ethics Board; Western University Research Ethics Board; Vancouver Island Health Authority Human Research Ethics Board; University of Northern British Columbia Research Ethics Board.

Provenance and peer review Not commissioned; externally peer reviewed.

Data sharing statement No additional data are available.

Open Access This is an Open Access article distributed in accordance with the Creative Commons Attribution Non Commercial (CC BY-NC 4.0) license, which permits others to distribute, remix, adapt, build upon this work noncommercially, and license their derivative works on different terms, provided the original work is properly cited and the use is non-commercial. See: http:// creativecommons.org/licenses/by-nc/4.0/

\section{REFERENCES}

1. Health Canada. Report on the findings of the oral health component of the Canadian Health Measures Survey 2007-2009. Ottawa, ON: Health Canada, 2010. http://www.fptdwg.ca/assets/PDF/CHMS/ CHMS-E-tech.pdf (accessed 20 Jan 2015).

2. Marmot M, Allen JJ. Social determinants of health equity. Am J Public Health 2014;104(S4):S517-19.

3. Whitehead M, Dahlgren G. Levelling up (part 1): a discussion paper on concepts and principles for tackling social inequities in health. WHO Collaborating Centre for Policy Research on Social Determinants of Health, University of Liverpool, 2006.

4. World Health Organization. Monitoring health inequality: an essential step for achieving health equity. Geneva, Switzerland: World Health Organization, 2014. http://apps.who.int/iris/bitstream/10665/133849/ 1/WHO_FWC_GER_2014.1_eng.pdf?ua=1

5. UCL Institute of Health Equity. Marmot indicators 2014. September 2014 edn. London, England: UCL Institute of Health Equity \& The Marmot Review, 2014.

6. World Health Organization. Social determinants of health: what are social determinants of health?http://www.who.int/social_ determinants/sdh_definition/en/index.html (accessed 9 Aug 2013).

7. Thompson $\mathrm{B}$, Cooney $\mathrm{P}$, Lawrence $\mathrm{H}$, et al. Cost as a barrier to accessing dental care: findings from a Canadian population-based study. J Public Health Dent 2014;74:210-18.
8. Sanmartin C, Hennessy D, Lu Y, et al. Trends in out-of-pocket health care expenditures in Canada, by household income, 1997 to 2009. Health Rep 2014;25:13-17.

9. Organisation for Economic Cooperation and Development. Focus on top incomes and taxation in OECD countries: was the crisis a game changer? OECD, 2014. http://www.oecd.org/els/soc/

OECD2014-FocusOnToplncomes.pdf (accessed 20 Jan 2015).

10. Royal Commission on Aboriginal Peoples. Report of the Royal Commission on Aboriginal peoples: Volume 3, gathering strength. Ottawa: Royal Commission on Aboriginal Peoples, 1996. http://caid. ca/RRCAP3.0.pdf (accessed 28 Oct 2014).

11. First Nations Information Governance Centre. Report on the findings of the First Nations Oral Health Survey (FNOHS) 2009-2010. Ottawa, ON: First Nations Information Governance Centre, 2012. http://fnigc.ca/sites/default/files/docs/fn_oral_health_survey_ national_report_2010.pdf (accessed 20 Jan 2015).

12. Health Canada. Summary report: Inuit Oral Health Survey 20082009. Ottawa, ON: Health Canada, 2011. http://publications.gc.ca/ collections/collection_2011/sc-hc/H34-231-2-2011-eng.pdf (accessed 20 Jan 2015).

13. Figueiredo RLF, Hwang SW, Quiñonez C. Dental health of homeless adults in Toronto, Canada. J Public Health Dent 2013;73:74-8.

14. Ramraj C, Sadeghi L, Lawrence HP, et al. Is accessing dental care becoming more difficult? Evidence from Canada's middle-income population. PLOS ONE 2013;8:e57377.

15. Quiñonez C, Figueiredo R. Sorry doctor, I can't afford the root canal, I have a job: Canadian dental care policy and the working poor. Can J Public Health 2010;101:481-5.

16. Yao CS, MacEntee MI, Prostho D. Inequity in oral health care for elderly Canadians: Part 1. Oral health status. J Can Dent Assoc 2013;79:d114

17. Wallace BB, MacEntee MI. Access to dental care for low-income adults: perceptions of affordability, availability and acceptability. $J$ Community Health 2012;37:32-9.

18. Patrick DL, Lee RSY, Nucci M, et al. Reducing oral health disparities: a focus on social and cultural determinants. BMC Oral Health 2006;6(Suppl 1):S4.

19. Quiñonez C, Grootendorst P. Equity in dental care among Canadian households. Int J Equity Health 2011;10:14.

20. Schrimshaw EW, Siegel K, Wolfson $\mathrm{NH}$, et al. Insurance-related barriers to accessing dental care among African American adults with oral health symptoms in Harlem, New York City. Am J Public Health 2011;101:1420-8.

21. Canadian Academy of Health Sciences. Improving access to oral health care for vulnerable people living in Canada. Ottawa, ON Canadian Academy of Health Sciences, 2014. http://www.cahs-acss ca/wp-content/uploads/2014/09/Access_to_Oral_Care_FINAL_ REPORT EN.pdf (accessed 22 Sep 2015).

22. Bedos C, Brodeur J-M, Boucheron L, et al. The dental care pathway of welfare recipients in Quebec. Soc Sci Med 2003;57:2089-99.

23. Quiñonez C, Figueiredo R, Azarpazhooh A, et al. Public preferences for seeking publicly financed dental care and professional preferences for structuring it. Community Dent Oral Epidemiol 2010;38:152-8.

24. Pegon-Machat E, Tubert-Jeannin S, Loignon C, et al. Dentists' experience with low-income patients benefiting from a public insurance program. Eur J Oral Sci 2009;117:398-406.

25. U. S. Department of Health and Human Services. Oral health in America: a report of the Surgeon General. Rockville, MD: US Department of Health and Human Services, US Public Health Service, National Institute of Dental and Craniofacial Research, National Institutes of Health, 2000. http://silk.nih.gov/public/hck1ocv. @ www.surgeon.fullrpt.pdf (accessed 20 Jan 2015).

26. Browne AJ, Varcoe CM, Ford-Gilboe M, et al. EQUIP Healthcare: an overview of a multi-component intervention to enhance equityoriented care in primary health care settings. Int $J$ Equity Health. In press.

27. Statistics Canada. Canadian Health Measures Survey (CHMS). http://www23.statcan.gc.ca/imdb/p2SV.pl?

Function=getSurvey\&SDDS=5071 (accessed 8 Sep 2014).

28. Statistics Canada. Canadian Community Health Survey (CCHS)2011 Questionnaire and reporting guide. http://www23.statcan.gc.ca/ imdb-bmdi/instrument/3226_Q1_V8-eng.htm (accessed 26 Sep 2012).

29. Comstock GW, Helsing KJ. Symptoms of depression in two communities. Psychol Med 1977;6:551-63.

30. Radloff LS. The CES-D Scale: a self-report depression scale for research in the general population. Appl Psychol Meas 1977;1:385-401.

31. Eaton WW, Smith C, Ybarra M, et al. Center for Epidemiologic Studies Depression Scale: review and revision (CESD and CESD-R). In: Maruish ME, ed. The use of psychological testing for 
treatment planning and outcomes assessment. 3rd edn. Mahwah, NJ: Lawrence Erlbaum Associates, 2004:363-77.

32. Von Korff M, Ormel J, Keefe FJ, et al. Grading the severity of chronic pain. Pain 1992:50:133-49.

33. Blanchard EB, Jones-Alexander J, Buckley TC, et al. Psychometric properties of the PTSD checklist (PCL). Behav Res Ther 1996;34:669-73.

34. Norris FH, Hamblen JL. Standardized self-report measures of civilian trauma and PTSD. In: Wilson JP, Keane TM, eds. Assessing psychological trauma and PTSD. 2nd edn. New York, NY: Guildford Press, 2004:63-102.

35. Statistics Canada. Table 109-5324-Unemployment rate, Canada, provinces, health regions (2013 boundaries) and peer groups, annual (percent), CANSIM (database).http://www5.statcan.gc.ca/ cansim/a26?lang=eng\& retrLang=eng\& $\mathrm{id}=1095324 \& \operatorname{tabMode}=$ dataTable\&srchLan=-1\&p1=-1\&p2=9\#F6 (accessed 21 Jan 2015).

36. Kneebone R, White $\mathrm{K}$. The rise and fall of social-assistance use in Canada, 1969-2012. University of Calgary, The School of Public Policy SPP Research Papers 2014;7:1-19.

37. Statistics Canada. Persons in low income after tax (in percent, 2007 to 2011). CANSIM table 202-0802 and Catalogue no. 75-202-X. http://www.statcan.gc.ca/tables-tableaux/sum-som/101/cst01/ famil19a-eng.htm?sdi=low\%20income (accessed 23 Jan 2015).

38. Segaert A. The National Shelter Study: emergency shelter use in Canada 2005-2009. Ottawa: Homelessness Partnering Secretariat, Human Resources and Skills Development Canada, 2012. http:// homelesshub.ca/sites/default/files/Homelessness\%20Partnering\% 20Secretariat\%202013\%20Segaert_0.pdf (accessed 21 Jan 2015).

39. Gaetz S, Donaldson J, Richter T, et al. The state of homelessness in Canada 2013. Toronto, ON: Canadian Homelessness Research Network Press, 2013

40. Statistics Canada. Table 105-0501- Health indicator profile, annual estimates, by age group and sex, Canada, provinces, territories, health regions (2012 boundaries) and peer groups, occasional, CANSIM (database). http://www5.statcan.gc.ca/cansim/a26? lang $=$ eng\&retrLang $=$ eng \& $\mathrm{id}=1050501 \&$ tabMode $=$ dataTable \& srchLan=-1\&p1=-1\&p2=9\#F16 (accessed 23 Jan 2015).

41. Ramraj C. Dental treatment needs in the Canadian population. University of Toronto, 2012.

42. Sanders AE, Spencer AJ. Why do poor adults rate their oral health poorly? Aust Dent J 2005;50:161-7.

43. Canadian Institute for Health Information. Emergency Department Trends, 2012-2013: how long do patients spend in the ED? National Ambulatory Care Reporting System (NACRS), Canadian Institute of Health Information, 2014. http://www.cihi.ca/ClHI-ext-portal/pdf/ internet/NACRS_EDT_INFOSHEET_EN (accessed 23 Jan 2015).
44. Canadian Institute for Health Information. What are health disparities? 2013. http://www.cihi.ca/ClHI-ext-portal/internet/EN/ document/health+system+performance/quality+of+care+and +outcomes/faq qc healthdisparities (accessed 9 Aug 2013).

45. Canadian Institute for Health Information. Disparities in primary health care experiences among Canadians with ambulatory care sensitive conditions. Ottawa, ON: Canadian Institute for Health Information, 2012. https://secure.cihi.ca/estore/productFamily.htm? locale $=$ en\&pf=PFC1712.

46. Pearson C, Janz T, Ali J. Mental health and substance use in Canada: health at a glance. Catalogue no.82-624-X. ISSN 1925-6493. Ottawa: Statistics Canada, 2013. http://www.statcan.gc.ca/pub/82-624-x/ 2013001/article/11855-eng.pdf (accessed 23 Jan 2015).

47. Pauly B, Cross G, Vallance K, et al. Facing homelessness: greater Victoria report on housing and Supports 2012/13. Victoria, BC: Greater Victoria Coalition to End Homelessness and Centre for Addictions Research of British Columbia, 2013. http://issuu.com/ victoriahomelessness/docs/gvceh reporthousingsupports final/3? $\mathrm{e}=5514930 / 4816130$ (accessed 23 Jan 2015).

48. Lévesque MC, Dupéré S, Loignon $\mathrm{C}$, et al. Bridging the poverty gap in dental education: how can people living in poverty help us? J Dent Educ 2009;73:1043-54.

49. Marmot M, Allen J, Goldblatt $\mathrm{P}$, et al. Fair society, healthy lives: the Marmot review executive summary. London: Marmot Review Team, 2010. http://www.instituteofhealthequity.org/projects/fairsociety-healthy-lives-the-marmot-review (accessed 20 Jan 2015).

50. Sheiham A, Alexander D, Cohen L, et al. Global oral health inequalities: task group-implementation and delivery of oral health strategies. Adv Dent Res 2011;23:259-67.

51. Watt RG. Social determinants of oral health inequalities: implications for action. Community Dent Oral Epidemiol 2012;40 (Suppl 2):44-8.

52. Petersen PE, Kwan S. Equity, social determinants and public health programmes-the case of oral health. Community Dent Oral Epidemiol 2011;39:481-7.

53. Northridge ME, Yu C, Chakraborty B, et al. A community-based oral public health approach to promote health equity. Am J Public Health 2015;105(Suppl 3):S459-65.

54. Wallace BB, MacEntee MI, Pauly B. Community dental clinics in British Columbia, Canada: examining the potential as health equity interventions. Health Soc Care Community 2015;23: 371-9.

55. Browne AJ, Varcoe C, Wong ST, et al. Closing the health equity gap: evidence-based strategies for primary health care organizations. Int J Equity Health 2012;11:1-15. 